CLINICAL STUDY

\title{
Natural course of untreated microalbuminuria in children and adolescents with type 1 diabetes and the importance of diabetes duration and immigrant status: longitudinal analysis from the prospective nationwide German and Austrian diabetes survey DPV
}

Angela Galler, Holger Haberland ${ }^{1}$, Andrea Näke ${ }^{2}$, Sabine Hofer ${ }^{3}$, Martin Holder ${ }^{4}$, Klemens Raile and Reinhard W Holl ${ }^{5}$ for the German Federal Ministry for Education and Research (BMBF) Competence Network of Diabetes Mellitus

Charité - Universitätsmedizin Berlin, Paediatric Endocrinology and Diabetology, University Hospital for Children and Adolescents, Campus Virchow Klinikum, Augustenburger Platz 1, 13353 Berlin, Germany, ${ }^{1}$ Sana Hospital Berlin Lindenhof, Hospital for Children and Adolescents, Gotlindestraße 2-20, 10365 Berlin, Germany, ${ }^{2}$ University Carl Gustav Carus Dresden, University Hospital for Children and Adolescents, Fetscherstr. 74, 01307 Dresden, Germany, ${ }^{3}$ Department of Paediatrics, Medical University of Innsbruck, Anichstrasse 35, 6020 Innsbruck, Austria, ${ }^{4}$ Klinikum Stuttgart, Olgahospital, Paediatric Endocrinology and Diabetology, Bismarckstraße 8, 70176 Stuttgart, Germany and ${ }^{5}$ Department of Epidemiology, University Ulm, Helmholtzstr. 22, 89081 Ulm, Germany

(Correspondence should be addressed to A Galler; Email: angela.galler@charite.de)

\begin{abstract}
Objective: To identify risk factors for the development and progression of untreated persistent microalbuminuria in children and adolescents with type 1 diabetes.

Design and methods: A total number of 683 children and adolescents with type 1 diabetes recruited from the prospective nationwide German and Austrian diabetes survey (DPV) were included in the analysis. Inclusion criteria were onset of type 1 diabetes under the age of 11 years, diabetes duration of more than 1 year and continuous follow-up over 5 years with at least two documented urine analyses per year. Subjects treated with angiotensin-converting enzyme inhibitors were excluded. Risk factors such as sex, body mass index SDS, diabetes duration, HbA1c, total cholesterol, HDL-cholesterol, LDL-cholesterol, systolic and diastolic blood pressure, and immigrant status were analysed by logistic regression.

Results: At baseline (age 10.5 \pm 0.1 years, diabetes duration $4.6 \pm 2.4$ years and $\mathrm{HbA} 1 \mathrm{c} 7.4 \pm 1.1 \%$ ), $75.6 \%$ of children had normoalbuminuria, $15.7 \%$ had intermittent microalbuminuria, $8.6 \%$ had persistent microalbuminuria and $0.1 \%$ had macroalbuminuria. After a follow-up of 5 years, $59.4 \%$ of adolescents continued to have normoalbuminuria, $18.4 \%$ had progression, $15.2 \%$ had regression of microalbuminuria, and in $6.9 \%$ of the subjects, microalbuminuria remained unchanged. We found significant associations between persistent microalbuminuria at baseline and during each year of follow-up $(P<0.0001)$. Logistic regression analysis identified diabetes duration and immigrant status as significant factors for microalbuminuria $(P=0.009$ and $P=0.009)$.

Conclusions: The survey in a real-world setting shows that diabetes duration and immigrant status are risk factors for the development and progression of untreated microalbuminuria in children and adolescents with type 1 diabetes.
\end{abstract}

European Journal of Endocrinology 166 493-501

\section{Introduction}

Microalbuminuria is a common finding in type 1 diabetes and is found in 30-60\% of patients with a diabetes duration of 10-20 years (1, 2, 3, 4). Persistent microalbuminuria is an important predictor of the development of diabetic nephropathy and progressive renal insufficiency in adults with type 1 diabetes $(1,3,4)$. Progression to macroalbuminuria or overt diabetic nephropathy occurs in around $25-45 \%$ of adults with type 1 diabetes with persistent microalbuminuria over $\sim 10$ years $(1,5)$. Several risk factors, including poor glycaemic control and a long diabetes duration, have a considerable impact on the rate of progression $(1,4,6)$. Furthermore, persistent microalbuminuria is associated with the progression of other diabetes complications such as retinopathy and cardiovascular disease $(1,3,4)$. However, risk factors for the development of diabetic nephropathy, including glycaemic control, diabetes duration, hypertension, smoking and hyperlipidaemia, do not explain the risk of nephropathy entirely $(1,4)$. In particular, only a portion of patients with type 1 diabetes will develop nephropathy irrespective of glycaemic control $(1,2)$. Family studies with type 1 
diabetic siblings have shown that the risk of diabetic nephropathy is three- to four-fold higher if a sibling with diabetes has nephropathy, indicating that genetic factors play an important role $(1,7)$.

Microalbuminuria is one of the most frequent pathological findings in adolescents with type 1 diabetes. Several cross-sectional studies demonstrated that $6-25 \%$ of patients between 15 and 20 years of age develop microalbuminuria $(1,4,8,9,10)$. Because the natural history of microalbuminuria in adolescents with type 1 diabetes is often not as consistent and clear as in adults, there is ongoing discussion about predictors of persistent microalbuminuria and nephropathy $(4,8,11,12,13)$. Some studies have shown that half of the probands with type 1 diabetes and microalbuminuria have normoalbuminuria at the end of puberty $(4,11)$. Only a few longitudinal studies have focused on the natural history of microalbuminuria in adolescents with type 1 diabetes. Furthermore, little is known about the influence of sociodemographic factors on the natural course of untreated microalbuminuria in adolescents with type 1 diabetes. Therefore, the aim was to identify risk factors for the development and progression of untreated persistent microalbuminuria in children and adolescents with type 1 diabetes and childhood onset of diabetes in a real-world setting.

\section{Design and methods}

The German and Austrian diabetes survey (DPV) is a prospective nationwide survey of patients with type 1 diabetes in Germany and Austria. Demographic-, anthropometric- and diabetes-related data of patients with type 1 diabetes are recorded in 271 diabetes care centres. Local data-control authorities and the ethics committee approved data collection and anonymous analysis for study purposes. The participating centres are listed in the appendix. A total number of 33998 children and adolescents with the onset of type 1 diabetes under the age of 11 years were registered in the survey until March 2010. Inclusion criteria for the present survey were onset of diabetes under the age of 11 years, diabetes duration of more than 1 year and at least two documented urine analyses per year at the age of 11 years according to the International Society for Pediatric and Adolescent Diabetes (ISPAD) guidelines (screening for microalbuminuria recommended from age 9 with 5 years of diabetes duration or from age 11 with 2 years of diabetes duration respectively) (14). Exclusion criteria were concomitant diseases such as coeliac disease and treatment with antihypertensive drugs (e.g. angiotensin-converting enzyme (ACE) inhibitors) to avoid effects on urine albumin excretion rate (AER). In total, 2959 children between the age of 10 and 11 years fulfilled the criteria. The present survey included 683 subjects who were followed continuously from the age of 10 years over 5 years with at least two urine analyses per year. For the rest of the children, no continuous follow-up was available. Body mass index SDS (BMI SDS) and height SDS were calculated using the national reference data in Germany (15).

\section{Assessment of microalbuminuria and macroalbuminuria}

Screening for microalbuminuria was performed by the following methods: i) measurement of urine albumin-to-creatinine (UAC) ratio in a random spot urine collection; ii) $24 \mathrm{~h}$ collection with creatinine; and iii) timed (e.g. overnight) collection. Microalbuminuria was defined as an increased urine albumin excretion. Thresholds for microalbuminuria were AER $\geq 20 \mu \mathrm{g} / \mathrm{min}$ or UAC $\geq 2.5 \mathrm{mg} / \mathrm{mmol}$ according to the guidelines of the ISPAD and the American Diabetes Association (ADA) $(14,16)$. No instantaneous consecutive sampling and no specific time interval between urine samples within 1 year were required in the present survey. Macroalbuminuria was defined as AER $\geq 200 \mu \mathrm{g} / \mathrm{min}$ or UAC $\geq 35 \mathrm{mg} / \mathrm{mmol}(14,16)$. Based on the current guidelines and recommendations, and on the DCCT and EDIC study, persistent microalbuminuria was defined as at least two pathological urine albumin excretions per year $(1,14,17)$. Intermittent microalbuminuria was defined as one increased urine albumin excretion and at least one normal urine albumin excretion per year. If only two urine samples were available, and one was pathological and another was normal, classification could not be done and the results were not included in the analysis. Regression to normoalbuminuria from persistent microalbuminuria was defined as AER $<20 \mu \mathrm{g} / \mathrm{min}$ or UAC ratio $<2.5 \mathrm{mg} / \mathrm{mmol}$ in two out of three urine albumin tests in the following year respectively. Albumin and creatinine were measured by centre-specific laboratory methods that had to meet German internal and external quality requirements for laboratory analysis according to the guidelines of the German Medical Association (18).

\section{Risk factors}

We analysed the following independent factors for the development of persistent microalbuminuria and nephropathy by logistic regression: sex; BMI SDS; height SDS; diabetes duration; HbA1c; total cholesterol; HDL-cholesterol; LDL-cholesterol; systolic and diastolic blood pressure; and immigrant status.

HbA1c Glycaemic control was assessed as median HbA1c during each year and during the follow-up. Single-centre $\mathrm{HbA1c}$ values were standardised mathematically to the DCCT reference range of 4.05-6.05\% using the multiple of the mean method (MOM method) (19). 
Dyslipidaemia Lipid levels were assessed annually. Dyslipidaemia was diagnosed if at least one lipid parameter was increased and if more than half of the measurements were above the cut-off levels. The cut-off levels were $>200 \mathrm{mg} / \mathrm{dl}$ for total cholesterol, $>130 \mathrm{mg} / \mathrm{dl}$ for LDL-cholesterol and $<35 \mathrm{mg} / \mathrm{dl}$ for HDL-cholesterol.

Hypertension Systolic and diastolic blood pressure was measured according to the current guidelines. Agespecific normal values were obtained from the Task Force on Blood Pressure Control in Children and Adolescents (20). Hypertension was defined as a median value $>95$ th percentile of at least three independent measurements.

Immigrant status The survey provided self-reported information on the place of birth of the parents of the patients. Immigration status was defined as the place of birth of one or both parents in a country other than Germany or Austria.

\section{Statistical analysis}

We used SAS 9.1 statistical software for data evaluation and statistical analysis (SAS Institute Inc., Cary, NC, USA). The $\chi^{2}$-test was used to examine the associations between the rate of intermittent and persistent microalbuminuria at baseline and during each year of follow-up. Relative contribution of covariates (sex, BMI SDS, height SDS, immigrant status, diabetes duration, median $\mathrm{HbA1c}$, systolic and diastolic blood pressure, total cholesterol, HDL-cholesterol, LDL-cholesterol, and intermittent microalbuminuria) to the risk for nephropathy was analysed by multivariate logistic regression. We selected the covariates based on clinical criteria. Odds ratios are reported as point estimates and 95\% confidence intervals. Data are presented as medians and interquartile ranges and as means and S.D. where appropriate. Statistical significance was assumed at $P$ values of $<0.05$.

\section{Results}

\section{Cohort characteristics}

In the prospective survey, 683 patients at the age of 10 years were followed longitudinally for 5 years between 1995 and March 2010 with a total of 3415 patient-years of follow-up. The cohort analysed was representative for the 2959 patients between the age of 10 and 11 years and with the onset of type 1 diabetes under the age of 10 years registered in the survey. Age (mean 10.5 vs 10.5 years), diabetes duration (median 4.3 vs 4.3 years), age at diabetes onset (median 6.2 vs 6.1 years), male sex ( 51.4 vs $51.7 \%$ ), BMI SDS (mean +0.33 vs +0.38 ), HbAlc (median 7.3 vs $7.4 \%$ ), and the percentage of children and adolescents with type 1 diabetes and immigrant status (13.0 vs $14.6 \%$ ) were comparable.

Baseline characteristics of the 683 follow-up patients are shown in Table 1. At baseline, mean BMI SDS was +0.33 , median diabetes duration was 4.3 years and median $\mathrm{HbAlc}$ was $7.3 \%$ in the whole cohort. In children and adolescents with immigrant status, mean BMI SDS was $+0.49 \pm 0.77$ compared with $+0.31 \pm$ 0.79 in those with non-immigrant status. Subjects with immigrant status had a higher median $\mathrm{HbAlc}$ of $7.6 \%$ (10th percentile $6.2 \%$, lower interquartile $7.0 \%$, upper quartile $8.2 \%$ and 90 th percentile $8.8 \%$ ) compared with native-born children (median $\mathrm{HbA1c} 7.3 \%$ with 10 th percentile $6.1 \%$, lower interquartile $6.6 \%$, upper quartile $7.9 \%$ and 90 th percentile $8.86 \%$ ). Of those subjects with immigrant status, $26 \%$ were from Turkey, $35 \%$ from Eastern European countries (e.g. Poland, Romania, Ukraine, Belarus), $10 \%$ from Southeastern European countries (e.g. Bosnia and Herzegovina), 10\% from Northern Africa (e.g. Tunisia) and 19\% from various other countries (e.g. Chile). In the present survey, the average number of samples was $3.7 \pm 1.5$ urine analyses per participant per year. Overall, $44 \%$ of the subjects had two urine analyses per year, $27 \%$ had three analyses per year and $29 \%$ had more than three analyses per year.

Table 1 Baseline characteristics of the cohort.

\begin{tabular}{|c|c|c|c|c|}
\hline & \multicolumn{2}{|c|}{ All subjects $(n=683)$} & \multicolumn{2}{|c|}{ Subjects with microalbuminuria } \\
\hline & Non-immigrant & Immigrant & Intermittent & Persistent \\
\hline Number & 594 & 89 & 107 & 59 \\
\hline Immigrant status ( $n(\%))$ & & $89(13)$ & $17(15.9)$ & $9(15.3)$ \\
\hline Age (years) ${ }^{a}$ & $10.5 \pm 0.1$ & $10.5 \pm 0.1$ & $10.5 \pm 0.1$ & $10.5 \pm 0.1$ \\
\hline Gender ratio (male/female (\%)) & $51.0 / 49.0$ & $53.9 / 46.1$ & $49.5 / 50.5$ & $30.5 / 69.5$ \\
\hline BMI SDS $^{a}$ & $+0.31 \pm 0.79$ & $+0.49 \pm 0.77$ & $+0.33 \pm 0.81$ & $+0.35 \pm 0.76$ \\
\hline Diabetes duration (years) ${ }^{\mathrm{b}}$ & $4.5 \pm 3.9$ & $3.8 \pm 3.2$ & $4.5 \pm 2.5$ & $4.6 \pm 2.3$ \\
\hline Age at diabetes onset (years) ${ }^{\mathrm{b}}$ & $6.0 \pm 4.0$ & $6.7 \pm 3.0$ & $6.0 \pm 2.5$ & $5.9 \pm 2.3$ \\
\hline $\mathrm{HbA} 1 \mathrm{c}(\%)^{\mathrm{b}}$ & $7.3 \pm 1.3$ & $7.6 \pm 1.2$ & $7.3 \pm 1.0$ & $7.3 \pm 1.0$ \\
\hline Insulin dose $(\mathrm{IU} / \mathrm{kg})^{\mathrm{a}}$ & $0.81 \pm 0.22$ & $0.86 \pm 0.19$ & $0.81 \pm 0.21$ & $0.90 \pm 0.29$ \\
\hline Hypertension ( $n(\%))$ & $7(1.2)$ & $2(2.2)$ & $2(1.9)$ & $0(0)$ \\
\hline Dyslipidaemia ( $n(\%))$ & $104(17.5)$ & $8(9)$ & $2(1.9)$ & $0(0)$ \\
\hline
\end{tabular}

${ }^{a}$ Data is expressed as mean \pm s.D.

${ }^{\mathrm{b}}$ Data is expressed as median \pm interquartile range. 
At baseline (mean age $10.5 \pm 0.1$ years), $75.6 \%(n=516)$ of children had normoalbuminuria, $15.7 \%(n=107)$ had intermittent microalbuminuria, $8.6 \%(n=59)$ had persistent microalbuminuria and $0.1 \%(n=1)$ had macroalbuminuria. HbA1c levels in subjects with intermittent microalbuminuria were not different from those in subjects with persistent microalbuminuria. Characteristics of children and adolescents with intermittent and persistent microalbuminuria are described in Table 1.

\section{Progression and regression of microalbuminuria during the follow-up}

Out of the 516 children with normoalbuminuria at baseline, $406(78.7 \%)$ had stable normoalbuminuria after a continuous follow-up of 5 years. Of the 59 children with persistent microalbuminuria at baseline, 18 were male $(30.5 \%)$ and $41(69.5 \%)$ were female. Of these 59 patients, $17(28.8 \%)$ had unchanged persistent microalbuminuria, whereas $42(71.2 \%)$ had regression to intermittent microalbuminuria or normoalbuminuria. Figure 1 depicts the percentages of children with normoalbuminuria, intermittent and persistent microalbuminuria at baseline and after the follow-up of 5 years. In summary, out of the total cohort of 683 children, after the follow-up of 5 years, $59.4 \%$ $(n=406)$ had stable normoalbuminuria and $15.2 \%$ $(n=104)$ had regression from intermittent microalbuminuria to normoalbuminuria or from persistent microalbuminuria to intermittent microalbuminuria or normoalbuminuria. Finally, $18.4 \%(n=126)$ progressed

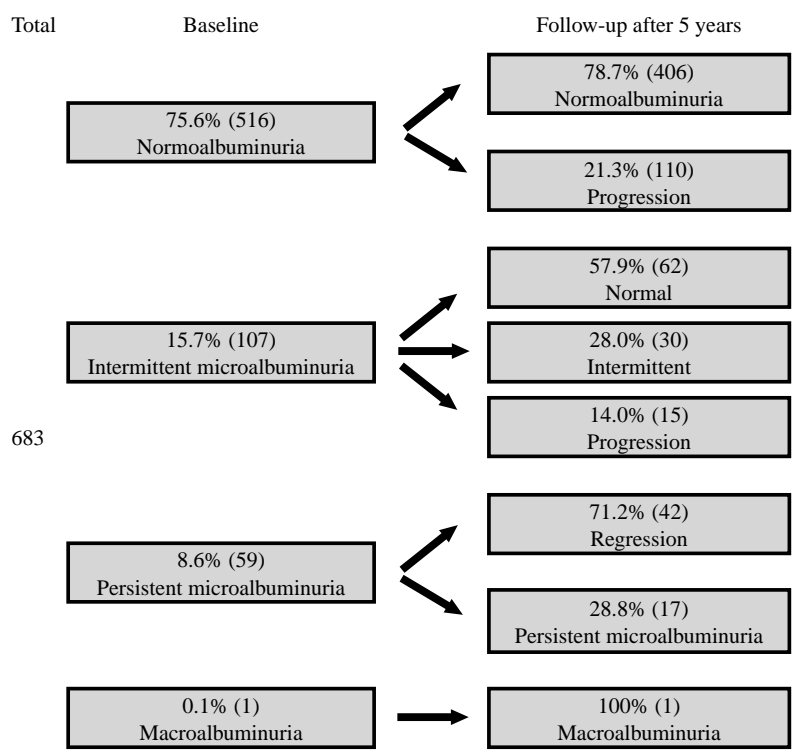

Figure 1 The rates (\% and absolute numbers) of the 683 children with type 1 diabetes with normoalbuminuria, intermittent and persistent microalbuminuria at baseline, and the progression and regression of microalbuminuria after a follow-up of 5 years are depicted. to intermittent or persistent microalbuminuria and $6.9 \%(n=47)$ had unchanged intermittent or persistent microalbuminuria.

There was no significant association between intermittent microalbuminuria at baseline and persistent microalbuminuria after the follow-up of 5 years $(P=0.10)$. We found significant associations between persistent microalbuminuria at baseline and during each year of follow-up $(P<0.0001)$.

\section{Regression analysis}

Multivariate logistic regression analysis with the variables sex, BMI SDS, height SDS, immigrant status, diabetes duration, HbAlc, systolic and diastolic blood pressure, total cholesterol, HDL-cholesterol, LDL-cholesterol, and intermittent microalbuminuria for the development or progression to microalbuminuria identified diabetes duration and immigrant status as significant risk factors for microalbuminuria $(P<0.01$; see Table 2). The progression rate of microalbuminuria in subjects with type 1 diabetes and immigrant status was significantly higher than that in subjects with non-immigrant status ( 26 vs $16 \%, P=0.03$ ).

In a second analysis, we analysed prediction factors for the regression of microalbuminuria in children and adolescents with type 1 diabetes. Multivariate logistic regression analysis including the factors sex, BMI SDS, immigrant status, diabetes duration, $\mathrm{HbA} 1 \mathrm{c}$, systolic and diastolic blood pressure, total cholesterol, HDL-cholesterol and LDL-cholesterol did not reveal any significant predictors for the regression of microalbuminuria after the follow-up of 5 years.

\section{Discussion}

To our knowledge, the present survey is the first to demonstrate that immigration status is an independent risk factor for the development of persistent microalbuminuria in children and adolescents with type 1 diabetes. The aim of this survey was to assess the natural history of microalbuminuria without any therapeutic intervention in a real-world setting in order to look for additional risk factors for the development and progression of microalbuminuria. Thus, because of the positive effects of ACE inhibitors on the regression of nephropathy, we excluded children and adolescents with concomitant medication $(1,4$, 14). The focus on the natural course of microalbuminuria, the large number of children in the survey in a real-world setting, and the very homogeneous cohort of children regarding age and diabetes duration are major strengths of the present survey. To date, little is known about the development of diabetic complications and comorbidities in type 1 diabetes in different population groups $(21,22,23,24)$. Differences in health status in immigrant and non-immigrant families may explain 
Table 2 Logistic regression analysis of risk factors for the progression of microalbuminuria after a follow-up of 5 years.

\begin{tabular}{|c|c|c|c|c|}
\hline & \multicolumn{2}{|c|}{$\begin{array}{l}\text { Simple model } \\
\text { (confounders adjusted for diabetes } \\
\text { duration only) }\end{array}$} & \multicolumn{2}{|c|}{$\begin{array}{l}\text { Complete model } \\
\text { (fully adjusted model) }\end{array}$} \\
\hline & Odds ratio & $(95 \% \mathrm{Cl})$ & Odds ratio & $(95 \% \mathrm{Cl})$ \\
\hline Sex (male vs female) & 0.886 & $(0.600 ; 1.307)$ & 0.968 & $(0.563 ; 1.664)$ \\
\hline BMI SDS & $0.759^{\dagger}$ & $(0.590 ; 0.977)^{\dagger}$ & 0.840 & $(0.583 ; 1.210)$ \\
\hline Height SDS & 1.034 & $(0.846 ; 1.265)$ & 1.185 & $(0.876 ; 1.602)$ \\
\hline Immigrant status (immigrant vs non-immigrant) & $1.803^{\dagger}$ & $(1.064 ; 3.055)^{\dagger}$ & $2.674^{*}$ & $(1.279 ; 5.590)^{*}$ \\
\hline Diabetes duration & $1.107^{\dagger}$ & $(1.020 ; 1.200)^{\dagger}$ & $1.170^{*}$ & $(1.040 ; 1.316)^{*}$ \\
\hline $\mathrm{HbA1c}$ & 1.009 & $(0.849 ; 1.200)$ & 1.018 & $(0.797 ; 1.299)$ \\
\hline Systolic blood pressure & 0.994 & $(0.973 ; 1.016)$ & 1.004 & $(0.971 ; 1.037)$ \\
\hline Diastolic blood pressure & 1.000 & $(0.971 ; 1.031)$ & 0.997 & $(0.953 ; 1.043)$ \\
\hline Total cholesterol & 0.995 & $(0.987 ; 1.003)$ & 1.001 & $(0.988 ; 1.014)$ \\
\hline HDL-cholesterol & 1.004 & $(0.996 ; 1.013)$ & 0.995 & $(0.975 ; 1.015)$ \\
\hline LDL-cholesterol & 0.994 & $(0.983 ; 1.005)$ & 0.995 & $(0.981 ; 1.009)$ \\
\hline $\begin{array}{l}\text { Intermittent microalbuminuria at baseline (presence } \\
\text { vs absence of intermittent microalbuminuria) }\end{array}$ & 0.686 & $(0.382 ; 1.233)$ & 0.549 & $(0.231 ; 1.305)$ \\
\hline
\end{tabular}

${ }^{\star} P<0.01 ;{ }^{\dagger} P<0.05$.

this newly found and interesting association between immigrant status and microalbuminuria. Principally, there is growing awareness of differences in health status between various population groups $(24,25,26$, 27, 28, 29, 30). The German Health Interview and Examination Survey for Children and Adolescents (KiGGS) conducted from 2003 to 2006 showed that general state of health is estimated to be lower in children with immigrant status compared with those with non-immigrant status (29). Childhood obesity is one example where prevalence differs significantly in population subgroups in Europe and in the USA: prevalence of overweight and obesity is higher in immigrant children compared with native-born children $(26,27)$. In the present survey, BMI SDS was also higher in children with immigrant status compared with those with non-immigrant status. However, further analysis showed that BMI SDS was not a significant risk factor for the development or progression of microalbuminuria. Disparities in lifestyle and nutrition habits may account for different health status in immigrant and non-immigrant families $(24,30)$. The KiGGS study reported considerable differences in food intake and dietary habits in children and adolescents with immigrant status compared with those with non-immigrant status (30). Besides health status, confounding factors associated with immigrant status possibly explain the observed association. Immigrant status is strongly associated with low socioeconomic status. And then again, socio-economic status is correlated with health status $(29,31)$. Regrettably, in the present survey, no data about socio-economic status were available. Additionally, in many countries, children and adolescents from immigrant families do not have equal access to health care compared with nonimmigrant families. However, in Germany and Austria, health insurance is either compulsory or part of the social security system. Therefore, it is not likely that different health care access accounts for the observed higher risk of microalbuminuria in children with immigrant status in the present survey. However, the use of health care facilities may well differ between immigrant and non-immigrant families. As one limitation of the present survey, no further data about health status, lifestyle or nutrition habits, socioeconomic parameters, and about the use of health care facilities were available. Another reason explaining the association between the development of microalbuminuria and immigrant status is the fact that incidence rates of type 1 diabetes in immigrant and nonimmigrant children are different (32). The percentage of children with type 1 diabetes who are not of German descent is smaller $(8.3 \%)$ compared with the percentage among the general population (15.2\%) (32). Causes for this observation are controversial (32). Therefore, incidence of diabetic complications could also be different in immigrant and non-immigrant children. Lastly and importantly, ethnic and genetic differences may have a considerable impact on the development of comorbidities. In type 2 diabetes, South Asians were reported to have a higher risk of developing retinopathy (23). With respect to diabetes in general, the incidence of nephropathy and end-stage renal disease is much higher for some population groups, such as Blacks, Asians and Latinos, compared with Caucasians (21, 22). Several studies have suggested an important genetic influence on nephropathy $(1,4,7)$. Some candidate genes, including mutations of the ACE gene, have been implicated to play a role $(1,4,6)$.

Besides the interesting finding that immigrant status is a significant risk factor for microalbuminuria, we confirmed in a real-world setting that a certain percentage of children have microalbuminuria already at a very young age $(1,2,8,9,10,33)$. In the present survey, $8.6 \%$ of children at the age of 10.5 years had persistent microalbuminuria. Other studies have 
reported similar results: the prevalence rate of microalbuminuria was estimated to be $5.9 \%$ in children with a mean age of 12.7 years and a diabetes duration of 5.1 years (4). Another study in children (mean age 12.9 years) has revealed that persistent microalbuminuria was present in $9.3 \%$ (13). The present survey also showed that intermittent microalbuminuria was not a predictive factor for the progression of microalbuminuria and that in a real-world setting, intermittent microalbuminuria has little prognostic significance in adolescents with type 1 diabetes $(1,4,12,14)$. Regression of microalbuminuria is well described in adults and is estimated to be between 30 and $64 \%(2,6,11,34)$. In adolescents with type 1 diabetes, regression rate is even higher $(4,11,33)$. Some longitudinal studies have suggested that more than $50 \%$ of cases with persistent microalbuminuria in adolescence revert to normoalbuminuria at the end of puberty $(4,11,13)$. However, in many longitudinal studies, a certain number of patients do receive treatment with antihypertensive drugs $(4,11,12,17,33,34,35,36)$. For instance, in the Oxford regional prospective study, cumulative prevalence of regression to normoalbuminuria was $51.9 \%$ after $\sim 5$ years after the onset of microalbuminuria (33). However, $15 \%$ of the subjects with microalbuminuria in this study received treatment with an ACE inhibitor or a $\beta$-blocker (33). In the present survey, regression rate of persistent microalbuminuria to intermittent microalbuminuria or normoalbuminuria without ACE inhibitor treatment was estimated at $71.2 \%$. This percentage is comparable to a recently published, small study, where 14 out of 17 patients ( $82 \%$ of patients) who had never received ACE inhibitors underwent spontaneous remission during a follow-up period of $13.1 \pm 6.2$ years (36).

Many studies have examined risk factors including glycaemic control, diabetes duration, sex, smoking, hypertension and disturbed lipid metabolism to determine and predict diabetic nephropathy $(1,2,3,4$, $5,6,35,37)$. Poor glycaemic control is found to be the most important factor associated with faster progression of AER in adolescents and adults with baseline microalbuminuria $(1,2,3,4,5,35,38)$. However, in the present survey we identified diabetes duration but not glycaemic control as predictive for the progression of microalbuminuria. Overall, metabolic control as measured by $\mathrm{HbA1} \mathrm{c}$ was relatively good in the present survey compared with other studies (HbAlc 7.4\% at baseline in the present survey vs $8.7 \%$ in the study by Alleyn et al. (13) or 9.3\% in the Nephropathy Family Study cohort (39)). The small number of patients with poor metabolic control in the present survey possibly explains the reason why we did not observe a significant association between $\mathrm{HbA} 1 \mathrm{c}$ levels and the presence of microalbuminuria. Furthermore, other studies showed that abnormal lipid profiles are risk factors for the development of microalbuminuria $(36,39)$. Especially, lower HDL-cholesterol levels are present in patients with type 1 diabetes and microalbuminuria (36). However, and in contrast to those studies, we did not observe such an effect. Possible reasons are that in other studies, either age at baseline was higher (e.g. mean age 14.5 vs 10 years in the present survey) or the follow-up period was longer (e.g. 13 vs 5 years in the present survey) $(36,39)$. Therefore, the effect of abnormal lipid levels is probably more evident in those studies. Subsequently, puberty might influence the development of microalbuminuria (1). The probability of developing microalbuminuria is increased after the onset of puberty $(8,40)$. Regrettably, as we had no information about pubertal status in the present survey, we did not include this confounding factor in the analysis. Instead, we used height SDS because lower height could represent delayed puberty. Lower height could also indicate prior poor metabolic control or could be an additional risk factor as found by one published study (41). However, we did not observe any significant effect of height as a risk factor for the progression of microalbuminuria in the present survey.

Finally, several limitations of the present survey should be pointed out. A bias towards milder microalbuminuria is possible, because only children and adolescents without medication were included in the study (4). Secondly, continuous follow-up of the study subjects was only 5 years. Because of the limited duration of the study, no assumptions can be made about further progression to macroalbuminuria and overt nephropathy. Lastly, weak to moderate predictors and correlations could possibly not be demonstrated because of limited power.

In summary, the so-far established risk factors for nephropathy in type 1 diabetes do not completely explain the development of micro- and macroalbuminuria $(1,4)$. We demonstrated for the first time that immigrant status is a relevant risk factor for microalbuminuria and has a considerable impact on the progression of persistent microalbuminuria in children and adolescents with type 1 diabetes in a real-world setting. This finding may be in part due to genetic causes or to modifiable and confounding socio-economic and lifestyle factors associated with health status in immigrant and non-immigrant children. In order to confirm the results of this study and to look for underlying causes explaining the association of microalbuminuria and immigrant status further multicentre studies are needed.

\section{Declaration of interest}

The authors declare that there is no conflict of interest that could be perceived as prejudicing the impartiality of the research reported.

\section{Funding}

This study was funded by the German Federal Ministry for Education and Research (BMBF) (FKZ 01GI0859), the German Diabetes Association, the Dr Bürger-Büsing Foundation and Novo Nordisk, Germany. 


\section{Acknowledgements}

We kindly acknowledge the participating diabetes centres in Germany and Austria.

We thank the following diabetes care centres for participating in the survey: Aachen-Uni-Kinderklinik RWTH; Aalen Kinderklinik; Ahlen St Franziskus Kinderklinik; Altötting Zentrum Inn-Salzach; Arnsberg-Hüsten Karolinenhosp. Kinderabteilung; Asbach KamillusKlinik Innere, Aue Helios Kinderklink; Augsburg Kinderklinik Zentralklinikum; Aurich Kinderklinik; Bad Aibling Internist. Praxis; Bad Hersfeld Kinderklinik; Bad Kösen Kinder-Rehaklinik; Bad Lauterberg Diabeteszentrum Innere; Bad Mergentheim Gemeinschaftspraxis DM-dorf Althausen; Bad Oeynhausen Herz-und Diabeteszentrum NRW; Bad Orb Spessart Klinik; Bad Reichenhall Innere; Bad Waldsee Kinderarztpraxis; Bautzen Oberlausitz KK; Berchtesgaden CJD; Berchtesgaden MVZ Innere Med; Berlin DRK-Kliniken; Berlin Kinderklinik Lindenhof; Berlin Klinik St Hedwig Innere; Berlin St Josephskrankenhaus Innere; Berlin Virchow-Kinderklinik; Berlin Vivantes Hellersdorf Innere; Bielefeld Kinderklinik Gilead; Bocholt Kinderklinik; Bochum Universitätskinderklinik St Josef; Bonn UniKinderklinik; Bottrop Knappschaftskrankenhaus Innere; Bremen Kinderklinik Nord; Bremen Mitte Innere; Bremen Kinderklinik St Jürgenstrasse; Bremerhaven Kinderklinik; Celle Kinderklinik; Chemnitz Kinderklinik; Chemnitz-Hartmannsdorf Innere Medizin DIAKOMED-1; Coesfeld Kinderklinik; Darmstadt Innere Medizin Darmstadt Kinderklinik Prinz. Margareth; Datteln Vestische Kinderklinik; Deggendorf Kinderarztpraxis; Delmenhorst Kinderklinik; Detmold Kinderklinik; Dornbirn Kinderklinik; Dortmund Kinderklinik; Dortmund Knappschaftskrankenhaus Innere; Dortmund Medizinische Kliniken Nord; Dortmund-St Josefshospital Innere; Dresden Neustadt Kinderklinik; Dresden Uni-Kinderklinik; Duisburg Evang. und Johanniter Krhs, Innere; Duisburg Malteser St Anna Innere; DürenBirkesdorf Kinderklinik; Düsseldorf Uni-Kinderklinik, Eberswalde Klinikum Barnim Werner Forßmann Innere; Erfurt Kinderklinik; Erlangen Uni-Kinderklinik; Essen Diabetes-Schwerpunktpraxis Dr Best; Essen Elisabeth Kinderklinik; Essen Uni-Kinderklinik; Esslingen Städtische Kinderklinik; Eutin Kinderklinik; Frankenthal Kinderarztpraxis; Frankfurt Bürgerhospital; Frankfurt Uni-Kinderklinik; Frankfurt Uni-Klinik Innere; Freiburg Uni Innere; Freiburg UniKinderklinik; Friedberg Innere Klinik; Friedrichshafen Kinderklinik; Fulda Innere Medizin; Fulda Kinderklinik; Fürth Kinderklinik; Gaissach Fachklinik der Deutschen Rentenversicherung Bayern; GarmischPartenkirchen Kinderklinik; Geislingen Klinik Helfenstein Innere; Gelnhausen Innere; Gelnhausen Kinderklinik; Gelsenkirchen Kinderklinik Marienhospital; Gera Kinderklinik; Gießen Uni-Kinderklinik; Graz Universitäts-Kinderklinik; Göppingen Innere Medizin; Göppingen Kinderklinik am Eichert; Görlitz Städtische Kinderklinik; Göttingen Uni-Kinderklinik; Hachenburg Kinderpraxis; Hagen Kinderklinik; Halle Uni-Kinderklinik; Halle-Dölau Städtische Kinderklinik; Hamburg Altonaer Kinderklinik; Hamburg Endokrinologikum; Hamburg Kinderklinik Wilhelmstift; Hamburg-Nord Kinderklinik Heidberg; Hameln Kinderklinik; Hamm Kinderklinik; Hanau Kinderklinik; Hanau St Vincenz - Innere; Hannover Kinderklinik MHH; Hannover Kinderklinik auf der Bult; Haren Kinderarztpraxis; Heide Kinderklinik; Heidelberg Uni-Kinderklinik; Heidenheim Kinderklinik; Heilbronn Innere Klinik; Heilbronn Kinderklinik; Herdecke Kinderklinik; Herford Kinderarztpraxis; Herford Klinikum Kinder \& Jugendliche; Heringsdorf Inselklinik; Hermeskeil Kinderpraxis; Herten St Elisabeth Innere Medizin; Hildesheim Innere; Hildesheim Kinderarztpraxis; Hildesheim Kinderklinik; Hinrichsegen-Bruckmühl Diabetikerjugendhaus; Hof Kinderklinik; Homburg Uni-Kinderklinik Saarland; Idar Oberstein Innere; Ingolstadt Klinikum Innere; Innsbruck Universitätskinderklinik; Iserlohn Innere Medizin; Itzehoe Kinderklinik; Jena UniKinderklinik; Kaiserslautern-Westpfalzklinikum Kinderklinik; Karlsburg Klinik für Diabetes \& Stoffwechsel; Karlsruhe Städtische Kinderklinik; Kassel Kinderklinik Park Schönfeld; Kassel Städtische Kinderklinik; Kaufbeuren Innere Medizin; Kempen Heilig Geist Innere; Kiel Städtische Kinderklinik; Kiel Universitäts-Kinderklinik; Kirchen DRK Klinikum Westerwald, Kinderklinik; Kirchheim-Nürtingen Innere; Koblenz Kemperhof 1. Med. Klinik; Koblenz Kinderklinik Kemperhof; Konstanz Innere Klinik; Konstanz Kinderklinik; Krefeld
Innere Klinik; Krefeld Kinderklinik; Kreischa-Zscheckwitz, Klinik Bavaria; Köln Kinderklinik Amsterdamerstrasse; Köln Uni-Kinderklinik; Landshut Kinderklink; Leipzig Uni-Kinderklinik; Leverkusen Kinderklinik; Limburg Innere Medizin; Lindenfels Luisenkrankenhaus Innere; Lingen Kinderklinik St Bonifatius; Linz Innere Medizin; Linz Kinderklinik; Lippstadt Evangelische Kinderklinik; Ludwigsburg Kinderklinik; Ludwigshafen Kinderklinik St Anna-Stift; Lübeck Uni-Kinderklinik; Lübeck Uni-Klinik Innere Medizin; Lüdenscheid Kinderklinik; Magdeburg Städtisches Klinikum Innere; Magdeburg Uni-Kinderklinik; Mainz Uni-Kinderklinik; Mannheim - Innere; Mannheim Uni-Kinderklinik; Marburg Uni Innere; Marburg UniKinderklinik; Mechernich Kinderklinik; Memmingen Kinderklinik; Merzig Kinderklinik; Minden Kinderklinik; Moers St Josefskrankenhaus Innere; Moers Kinderklinik; Mutterstadt Kinderarztpraxis; Mönchengladbach Kinderklinik Rheydt Elisabethkrankenhaus; Mühlacker Enzkreiskliniken Innere; München 3. Orden Kinderklinik; München Diabetes-Zentrum Süd; München Kinderarztpraxis Gavazzeni; München von Haunersche Kinderklinik; München-Gauting Kinderarztzentrum; München-Harlaching Kinderklinik; MünchenSchwabing Kinderklinik; Münster St Franziskus Kinderklinik; Münster Uni-Kinderklinik; Münster pädiat. Schwerpunktpraxis; Nauen Havellandklinik; Neuburg Kinderklinik; Neunkirchen Marienhausklinik Kohlhof Kinderklinik; Neunkirchen Praxis Kinder-und Jugendpsychiatrie; Neuss Lukaskrankenhaus Kinderklinik; Neuwied Kinderklinik Elisabeth; Nürnberg Cnopfsche Kinderklinik; Nürnberg Zentrum f Neugeb., Kinder \& Jugendliche; Oberhausen Innere; Oberhausen Kinderklinik; Oberhausen Kinderpraxis Bachran; Offenbach/Main Kinderklinik; Offenburg Kinderklinik; Oldenburg Kinderklinik; Oldenburg Schwerpunktpraxis; Osnabrück Kinderklinik; Oy-Mittelberg Hochgebirgsklinik Kinder-Reha; Paderborn St Vincenz Kinderklinik; Papenburg Marienkrankenhaus Kinderklinik; Passau Kinderarztpraxis Handwerker; Passau Kinderklinik; Pforzheim Kinderklinik; Pirmasens Städtisches Krankenhaus Innere; Prenzlau Krankenhaus Innere; Rastatt Gemeinschaftspraxis; Ravensburg Kinderklink St Nikolaus; Recklinghausen Dialysezentrum Innere; Regensburg Kinderklinik St Hedwig; Remscheid Kinderklinik; Rendsburg Kinderklinik; Reutlingen Kinderarztpraxis; Reutlingen Klinikum Steinenberg Innere; Rheine Mathiasspital Kinderklinik; Rosenheim Innere Medizin; Rosenheim Kinderklinik; Rosenheim Schwerpunktpraxis; Rostock Uni-Kinderklinik; Rostock Universität Innere Medizin; Rotenburg/Wümme Kinderklinik; Rüsselsheim Kinderklinik; Saaldorf-Surheim Diabetespraxis; Saalfeld Thüringenklinik Kinderklinik; Saarbrücken Kinderklinik Winterberg; Saarlouis Kinderklinik; Scheidegg; Reha-Kinderklinik Maximilian; Schw. Gmünd Margaritenhospital Kinderklinik; Schweinfurt Kinderklinik; Schwerin Innere Medizin; Schwerin Kinderklinik: Schwäbisch Hall Diakonie Kinderklinik; Siegen Kinderklinik; Singen Hegauklinik Kinderklinik; Sinsheim Innere; Spaichingen Innere; St Augustin Kinderklinik; Stade Kinderklinik; Stolberg Kinderklinik; Stuttgart Olgahospital Kinderklinik; Suhl Kinderklinik; Sylt Rehaklinik; Tettnang Innere Medizin; Traunstein Praxis Dr Voll; Trier Kinderklinik der Borromäerinnen; Trostberg Innere; Tübingen Uni-Kinderklinik; Ulm Endokrinologikum; Ulm Schwerpunktpraxis Bahnhofsplatz; Ulm Uni-Kinderklinik; Vechta Kinderklinik; Viersen Kinderklinik; Waiblingen Kinderklinik; Waldshut Kinderpraxis; Waldshut-Tiengen Kinderpraxis Biberbau; Weiden Kinderklinik; Weingarten Kinderarztpraxis; Wernberg-Köblitz SPP; Wien Uni-Kinderklinik; Wiesbaden Horst-Schmidt-Kinderkliniken; Wiesbaden Kinderklinik DKD; Wilhelmshaven Reinhard-NieterKinderklinik; Wilhelmshaven St Willehad Innere; Wittenberg Kinderklinik; Worms Kinderklinik; Wuppertal Kinderklinik.

\section{References}

1 Bogdanović R. Diabetic nephropathy in children and adolescents. Pediatric Nephrology 200823 507-525. (doi:10.1007/s00467007-0583-2)

2 Hovind P, Tarnow L, Rossing P, Jensen BR, Graae M, Torp I, Binder C \& Parving HH. Predictors for the development of 
microalbuminuria and macroalbuminuria in patients with type 1 diabetes: inception cohort study. BMJ $2004 \mathbf{3 2 8} 1105-1109$. (doi:10.1136/bmj.38070.450891.FE)

3 Vergouwe Y, Soedamah-Muthu SS, Zgibor J, Chaturvedi N, Forsblom C, Snell-Bergeon JK, Maahs DM, Groop PH, Rewers M, Orchard TJ, Fuller JH \& Moons KG. Progression to microalbuminuria in type 1 diabetes: development and validation of a prediction rule. Diabetologia 201053 254-262. (doi:10.1007/ s00125-009-1585-3)

4 Chiarelli F, Trotta D, Verrotti A \& Mohn A. Treatment of hypertension and microalbuminuria in children and adolescents with type 1 diabetes mellitus. Pediatric Diabetes 20023 113-124. (doi:10.1034/j.1399-5448.2002.30209.x)

5 Rossing P, Hougaard P \& Parving HH. Risk factors for development of incipient and overt diabetic nephropathy in type 1 diabetic patients: a 10-year prospective observational study. Diabetes Care 200225 859-864. (doi:10.2337/diacare.25.5.859)

6 William J, Hogan D \& Batlle D. Predicting the development of diabetic nephropathy and its progression. Advances in Chronic Kidney Disease 200512 202-211. (doi:10.1053/j.ackd.2005.02. 001)

7 Rogus JJ, Poznik GD, Pezzolesi MG, Smiles AM, Dunn J, Walker W, Wanic K, Moczulski D, Canani L, Araki S, Makita Y, Warram JH \& Krolewski AS. High-density single nucleotide polymorphism genome-wide linkage scan for susceptibility genes for diabetic nephropathy in type 1 diabetes: discordant sibpair approach. Diabetes 200857 2519-2526. (doi:10.2337/db07-1086)

8 Gallego PH, Bulsara MK, Frazer F, Lafferty AR, Davis EA \& Jones TW. Prevalence and risk factors for microalbuminuria in a population-based sample of children and adolescents with T1DM in Western Australia. Pediatric Diabetes 20067 165-172. (doi:10. 1111/j.1399-543X.2006.00164.x)

9 Dost A, Klinkert C, Kapellen T, Lemmer A, Naeke A, Grabert M, Kreuder J \& Holl RW \& DPV Science Initiative. Arterial hypertension determined by ambulatory blood pressure profiles: contribution to microalbuminuria risk in a multicenter investigation in 2,105 children and adolescents with type 1 diabetes. Diabetes Care 200831 720-725. (doi:10.2337/dc07-0824)

10 Perrin NE, Torbjörnsdotter T, Jaremko GA \& Berg UB. Risk markers of future microalbuminuria and hypertension based on clinical and morphological parameters in young type 1 diabetes patients. Pediatric Diabetes 201011 305-313. (doi:10.1111/j.1399-5448. 2009.00595.x)

11 Steinke JM, Sinaiko AR, Kramer MS, Suissa S, Chavers BM \& Mauer M \& International Diabetic Nephropathy Study Group. The early natural history of nephropathy in type 1 diabetes: III. Predictors of 5-year urinary albumin excretion rate patterns in initially normoalbuminuric patients. Diabetes $2005 \mathbf{5 4}$ 2164-2171. (doi:10.2337/diabetes.54.7.2164)

12 Stone ML, Craig ME, Chan AK, Lee JW, Verge CF \& Donaghue KC. Natural history and risk factors for microalbuminuria in adolescents with type 1 diabetes: a longitudinal study. Diabetes Care 200629 2072-2077. (doi:10.2337/dc06-0239)

13 Alleyn CR, Volkening LK, Wolfson J, Rodriguez-Ventura A, Wood JR \& Laffel LM. Occurrence of microalbuminuria in young people with type 1 diabetes: importance of age and diabetes duration. Diabetic Medicine 201027 532-537. (doi:10.1111/j. 1464-5491.2010.02983.x)

14 Donaghue K, Chiarelli F, Trotta D, Allgrove J \& Dahl-Jorgensen K \& ISPAD Clinical Practice Consensus Guidelines 2009 Compendium. Microvascular and macrovascular complications associated with diabetes in children and adolescents. Pediatric Diabetes 200910 195-203. (doi:10.1111/j.1399-5448.2009.00576.x)

15 Kromeyer-Hauschild K, Wabitsch M, Geller F, Ziegler A, Geiß HC, Hesse V, Hippel A v, Jäger U, Johnsen D, Kiess W, Korte W, Kunze D, Menner K, Müller M, Niemann-Pilatus A, Remer T, Schäfer T, Wittchen HU, Zabransky S, Zellner K \& Hebebrand J. Perzentile für den Body Mass Index für das Kindes- und Jugendalter unter Heranziehung verschiedener deutscher Stichproben. Monatsschrift für Kinderheilkunde 2001149 807-818. (doi:10.1007/s001120170107)
16 Sacks DB, Bruns DE, Goldstein DE, Maclaren NK, McDonald JM \& Parrott M. Guidelines and recommendations for laboratory analysis in the diagnosis and management of diabetes mellitus. Diabetes Care 200225 750-786. (doi:10.2337/diacare.25.4.750)

17 de Boer IH, Rue TC, Cleary PA, Lachin JM, Molitch ME, Steffes MW, Sun W, Zinman B \& Brunzell JD \& for the Diabetes Control and Complications Trial/Epidemiology of Diabetes Interventions and Complications Study Research Group. Long-term renal outcomes of patients with type 1 diabetes mellitus and microalbuminuria: an analysis of the Diabetes Control and Complications Trial/Epidemiology of Diabetes Interventions and Complications cohort. Archives of Internal Medicine 2011171 412-420. (doi:10.1001/ archinternmed.2011.16)

18 Richtlinie der Bundesärztekammer zur Qualitätssicherung laboratoriumsmedizinischer Untersuchungen. Deutsches Ärzteblatt 2008105 A341-A355.

19 Gerstl EM, Rabl W, Rosenbauer J, Gröbe H, Hofer SE, Krause U \& Holl RW. Metabolic control as reflected by HbA1c in children, adolescents and young adults with type- 1 diabetes mellitus: combined longitudinal analysis including 27,035 patients from 207 centers in Germany and Austria during the last decade. European Journal of Pediatrics 2008167 447-453. (doi:10.1007/ s00431-007-0586-9)

20 Update on the 1987 Task Force Report on High Blood Pressure in Children and Adolescents: a working group report from the National High Blood Pressure Education Program. National high blood pressure education program working group on hypertension control in children and adolescents. Pediatrics 199698 649-658.

21 Karter AJ, Ferrara A, Liu JY, Moffet HH, Ackerson LM \& Selby JV. Ethnic disparities in diabetic complications in an insured population. Journal of the American Medical Association 2002287 2519-2527. (doi:10.1001/jama.287.19.2519)

22 Lopes AA. End-stage renal disease due to diabetes in racial/ethnic minorities and disadvantaged populations. Ethnicity $\mathcal{E}$ Disease 200919 (Suppl 1) S1-47-51.

23 Raymond NT, Varadhan L, Reynold DR, Bush K, Sankaranarayanan S, Bellary S, Barnett AH, Kumar S \& O'Hare JP \& UK Asian Diabetes Study Retinopathy Study Group. Higher prevalence of retinopathy in diabetic patients of South Asian ethnicity compared with white Europeans in the community: a cross-sectional study. Diabetes Care 200932 410-415. (doi:10.2337/dc08-1422)

24 Carter PJ, Cutfield WS, Hofman PL, Gunn AJ, Wilson DA, Reed PW \& Jefferies C. Ethnicity and social deprivation independently influence metabolic control in children with type 1 diabetes. Diabetologia 2008 51 1835-1842. (doi:10.1007/s00125-008-1106-9)

25 O'Connell J, Yi R, Wilson C, Manson SM \& Acton KJ. Racial disparities in health status: a comparison of the morbidity among American Indian and U.S. adults with diabetes. Diabetes Care 2010 33 1463-1470. (doi:10.2337/dc09-1652)

26 Singh GK, Kogan MD \& Yu SM. Disparities in obesity and overweight prevalence among US immigrant children and adolescents by generational status. Journal of Community Health 200934 271-281. (doi:10.1007/s10900-009-9148-6)

27 Will B, Zeeb H \& Baune BT. Overweight and obesity at school entry among migrant and German children: a cross-sectional study. BMC Public Health 20055 45. (doi:10.1186/1471-2458-5-45)

28 McBean AM, Li S, Gilbertson DT \& Collins AJ. Differences in diabetes prevalence, incidence, and mortality among the elderly of four racial/ethnic groups: whites, blacks, hispanics, and asians. Diabetes Care 200427 2317-2324. (doi:10.2337/diacare.27.10. 2317)

29 Lange M, Kamtsiuris P, Lange C, Schaffrath Rosario A, Stolzenberg H \& Lampert T. Sociodemographic characteristics in the German Health Interview and Examination Survey for Children and Adolescents (KiGGS) - operationalisation and public health significance, taking as an example the assessment of general state of health. Bundesgesundheitsblatt, Gesundheitsforschung, Gesundheitsschutz 200750 578-589. (doi:10.1007/ s00103-007-0219-5) 
30 Kleiser C, Mensink GB, Neuhauser H, Schenk L \& Kurth BM. Food intake of young people with a migration background living in Germany. Public Health Nutrition 2010 13 324-330. (doi:10. 1017/S1368980009991030)

31 Singh GK \& Hiatt RA. Trends and disparities in socioeconomic and behavioural characteristics, life expectancy, and cause-specific mortality of native-born and foreign-born populations in the United States, 1979-2003. International Journal of Epidemiology 200635 903-919. (doi:10.1093/ije/dyl089)

$32 \mathrm{Neu}$ A, Willasch A, Ehehalt S, Kehrer M, Hub R \& Ranke MB. Diabetes incidence in children of different nationalities: an epidemiological approach to the pathogenesis of diabetes. Diabetologia 200144 (Suppl 3) B21-B26. (doi:10.1007/PL00002948)

33 Amin R, Widmer B, Prevost AT, Schwarze P, Cooper J, Edge J, Marcovecchio L, Neil A, Dalton RN \& Dunger DB. Risk of microalbuminuria and progression to macroalbuminuria in a cohort with childhood onset type 1 diabetes: prospective observational study. BMJ 2008336 697-701. (doi:10.1136/ bmj.39478.378241.BE)

34 Perkins BA, Ficociello LH, Silva KH, Finkelstein DM, Warram JH \& Krolewski AS. Regression of microalbuminuria in type 1 diabetes. New England Journal of Medicine 2003348 2285-2293. (doi:10. 1056/NEJMoa021835)

35 Svensson M, Eriksson JW \& Dahlquist G. Early glycemic control, age at onset, and development of microvascular complications in childhood-onset type 1 diabetes: a population-based study in northern Sweden. Diabetes Care 200427 955-962. (doi:10.2337/ diacare.27.4.955)

36 Salardi S, Balsamo C, Zucchini S, Maltoni G, Scipione M, Rollo A, Gualandi S \& Cicognani A. High rate of regression from micromacroalbuminuria to normoalbuminuria in children and adolescents with type 1 diabetes treated or not with enalapril: the influence of HDL cholesterol. Diabetes Care 201134 424-429. (doi:10.2337/dc10-1177)
37 Raile K, Galler A, Hofer S, Herbst A, Dunstheimer D, Busch P \& Holl RW. Diabetic nephropathy in 27,805 children, adolescents, and adults with type 1 diabetes: effect of diabetes duration, A1C, hypertension, dyslipidemia, diabetes onset, and sex. Diabetes Care 200730 2523-2528. (doi:10.2337/dc07-0282)

38 The Diabetes Control and Complications Trial Research Group. The effect of intensive treatment of diabetes on the development and progression of long-term complications in insulin-dependent diabetes mellitus. New England Journal of Medicine 1993329 977-986. (doi:10.1056/NEJM199309303291401)

39 Marcovecchio ML, Dalton RN, Prevost AT, Acerini CL, Barrett TG, Cooper JD, Edge J, Neil A, Shield J, Widmer B, Todd JA \& Dunger DB. Prevalence of abnormal lipid profiles and the relationship with the development of microalbuminuria in adolescents with type 1 diabetes. Diabetes Care 200932 658-663. (doi:10.2337/dc08-1641)

40 Riihimaa PH, Knip M, Hirvelä H \& Tapanainen P. Metabolic characteristics and urine albumin excretion rate in relation to pubertal maturation in type 1 diabetes. Diabetes/Metabolism Research and Reviews 200016 269-275. (doi:10.1002/15207560(2000)9999:9999<::AID-DMRR121>3.0.CO;2-Z)

41 Wadén J, Forsblom C, Thorn LM, Saraheimo M, RosengårdBärlund M, Heikkilä O, Hietala K, Ong K, Wareham N \& Groop PH \& FinnDiane Study Group. Adult stature and diabetes complications in patients with type 1 diabetes: the FinnDiane Study and the diabetes control and complications trial. Diabetes $2009 \mathbf{5 8}$ 1914-1920. (doi:10.2337/db08-1767)

Received 8 April 2011

Revised version received 12 December 2011

Accepted 23 December 2011 